\title{
Supplementation of Vitamin A and $C$ can effectively recover the Histological and Haematological Alteration caused by Mosquito Coil Smoke and Aerosol in Mice Model
}

\author{
Moni Krishno Mohanta*, Alpona Sarker Hasi, \\ Md. Fazlul Haque and Ananda Kumar Saha \\ Genetics and Molecular Biology Laboratory, Department of Zoology, \\ University of Rajshahi, Rajshahi-6205, Bangladesh \\ *Corresponding author
}

\section{Keywords}

Mosquito coil, aerosol, Albino mice,

Histopathology, Blood parameters and vitamin $\mathrm{A}$ and C

Article Info

Accepted: 07 April 2019 Available Online: 10 May 2019

\section{A B S T R A C T}

Mosquito coil and aerosol are the most frequently used insecticides to control mosquito population in residential area which may have toxic impact on human health. Two-step investigations were carried out to assess the probable toxic impacts of inhaling mosquito coil smoke and aerosol on the experimental albino mice Mus musculus L. under laboratory conditions. The first experiment was on some haematological parameters and histopathology of the lungs, while the second vital experiment was performed to observe the possible recovery from the toxicity of aerosol by supplementing vitamins $\mathrm{A}$ and $\mathrm{C}$ to the food stuff. A total of 20 albino rats were divided into four groups, consisting of five rats each. Group 1 served as the control with no exposure to mosquito coil smoke and aerosol sprays, while Groups 2, 3 and 4 were maintained as follows. Test animals of Group 2 were exposed to mosquito coil smoke produced by burning one mosquito coil for 8 hours daily over a period of 45 days in a partially ventilated room. Rats of Groups 3 and 4 were exposed to aerosol puffs for 4-5 sec, but the rats of Group 4 were allowed to feed on diets supplemented with vitamins A (12500 IU/gm.bw/day) and C (62.5 mg/gm.bw/day) in the same experimental chambers. For the first 15 days, histological microphotographs of the lung tissues of the control rats showed no abnormalities in structure, colour or appearance. While rats of Groups 2 and 3 showed remarkable changes including thickening and infiltration of mononuclear cells in the interstitial space, distortion of inter alveolar septa, congestion and haemorrhages in the alveoli, and hypertrophied and hyperplastic bronchiolar cells. These lesions progressed further during 30 and 45 days' post-exposure. Haematological data revealed significant increases in the total RBC and WBC counts $(\mathrm{P}<0.05)$ in both groups exposed to mosquito coil and aerosol. Differential counts of eosinophils and basophils showed marginal changes in both groups, but the neutrophils increased significantly $(\mathrm{P}<0.05)$ and the lymphocytes and monocytes were found to be decreased compared to the control rats. In Group 4 rats, as anticipated, the total RBC and WBC counts decreased in comparison with the control rats, and remarkable sign of reforming, repair and controlling were observed in lung tissues of the former. It is therefore inferred that vitamins A and C play an effective role against cellular toxicity. Thus, the findings of the present study strongly suggest that optimum doses of vitamins A and $\mathrm{C}$ as feed supplements might serve as a novel way to evade the problems of mosquito coil smoke and aerosol inhalations. 


\section{Introduction}

Mosquito have long been identified as the main vectors of human and animal diseases like malaria and dengue. This had made many families to adopt several methods to control mosquito populations around residential areas. To control mosquitoes the annual worldwide consumption of the four major types of residential insecticides productsaerosols, mosquito coils, liquid vaporisers and vaporizing units are in the billions of units (Krieger et al., 2003).

Mosquito coils are the preferred antimosquito products in low income communities because they are cheap and readily available (Mulla et al., 2001) and these coils are burned indoors as a common practice in many households of South America, Africa and Asian countries including Bangladesh, India, China, Thailand, Malaysia, Korea and Japan. A World Health Organization (WHO) report estimated the world wide annual consumption of mosquito coils to be approximately 29 billion pieces (WHO, 2005). Mosquito coils and aerosols were used every day in 66 of $76(87 \%)$ and 6 of $12(50 \%)$ households in Dhaka City, Bangladesh (Sultana et al., 2015).

Mosquito coils consists of an insecticide/repellent, organic fillers capable of burning with smouldering, binder and additives such as synergists, dyes and fungicides (Krieger et al., 2003). The most common active ingredients in mosquito coils are various pyrethroids that are effective against many genera of mosquitoes including Aedes, Anopheles and Mansonia (Krieger et al., 2003).

Mosquito coils are often used overnight in sleeping quarters where elevated exposure may occur, children and their parents are often exposed to this chemically complex mosquito coil smoke containing small particles $(1 \mu \mathrm{m})$, metal fumes and vapours that may reach the alveolar region of the lung (Cheng et al., 1992). Chang and Lin (1998) have found that the gas phase of mosquito coil smoke contain carbonyl compounds (formaldehyde and acetaldehyde) with properties that can produce strong irritating effects on the upper respiratory tract.

Despite the fact that inhaling mosquito coil smoke and aerosol may have potential adverse health effects, large populations in developing countries still use the coils and aerosol in their daily lives. The objectives of the present study was to examine the effects of inhaling mosquito coil smoke and aerosol on the hematology and histology of the lung of albino rats along with recovery of the damage tissue by vitamin A \& C with hope that the results would provide a guide line for proper use these coils.

\section{Materials and Methods}

\section{Test animals}

Twenty healthy and sexually mature female albino mice Mus musculus L. (Rodentia: Muridae) weighing $44.78 \pm 2.80 \mathrm{~g}$ were collected from locally (Rajshahi) and reared in the Laboratory. Animals were kept in cages $(20 \times 14.50 \times 15.50 \mathrm{inch})$ with saw dust bedding in the laboratory under constant temperature $\left(33 \pm 4^{0} \mathrm{C}\right)$ and throughout the experiment work, being maintained on a stranded diet composed of maize grain $(36.92 \%)$, rice polish (18.46\%), wheat polish (24.62\%), soybean $(18.46 \%)$, crude protein $(1.23 \%)$ and salt and large grain premix $(0.15 \%$ each $)$, supplied twice daily and all the mice had access to drinking water ad libitum. In compliance with the standard animal ethical guidelines, the present investigation was carried out at the Laboratory of Genetics and Molecular Biology, Department of Zoology, University of Rajshahi, Bangladesh. 


\section{Test chemical}

Mosquito coil, aerosol, vitamin A and vitamin $\mathrm{C}$ were purchased from local market of Rajshahi Division.

\section{Experimental design}

Twenty albino mice were divided into four groups, consisting of five mice each. Group 1 served as the control with no exposure to mosquito coil smoke and aerosol sprays, while Groups 2, 3 and 4 were maintained as follows. Test animals of Group 2 were exposed to mosquito coil smoke produced by burning one mosquito coil for 8 hours daily over a period of 45 days in a partially ventilated room. Rats of Groups 3 and 4 were exposed to aerosol puffs for 4-5 sec, but the rats of Group 4 were allowed to feed on diets supplemented with vitamins A (12500 IU/gm.bw/day) and C (62.5 mg/gm.bw/day) in the same experimental chambers.

\section{Biochemical analysis of blood}

The blood sample was collected by cardiac puncture through $5 \mathrm{ml}$ needle syringe after sacrificing animal. All the blood was transferred into a tube for complete blood count (CBC) analysis and for hematological parameters like total count of $\mathrm{WBC}, \mathrm{RBC}$ and differential count of WBC. The biochemical analysis of blood parameters were done with 10 replication of each parameter according by Human Germany protocol, 2009-10. The data obtained on biochemical studies were subjected to statistically analysis using student's t-test.

\section{Histopathology}

Each of the 4 rats of every group was dissected after 15 days, 30 days, and 45 days interval and the lung carefully removed. This organ was rinsed in $0.85 \%$ saline solution for three times to remove any blood and debris attached on the external surface. Then the tissue was cut into small pieces of approximately 2-4 $\mathrm{mm}$ and fixed in Bouin's fluid for 18 hours. After fixation, tissues were dehydrated through ascending grades of ethanol. Thereafter, it was cleared in xylene and finally embedded in paraffin wax with a $58-60^{\circ} \mathrm{C}$ melting point. Paraffin sections were cut at $6 \mu \mathrm{m}$ using a rotary microtome; the sections were mounted on clear slides and stained with haematoxylin and eosin. Observation was made using a binocular compound microscope and photographs were taken with a digital Motic advanced biological microscope (B1 series) and microphotographs were made by the help of motic image J.1 software in machintash computer.

\section{Results and Discussion}

\section{Clinical symptoms}

Following exposure to mosquito coil smoke and aerosol the exposed rats showed nasal and oral irritation, perinasal and perioral wetness and uncomfortable movements in exposure chamber but they recovered from such clinical symptoms as they were out of exposures. There was normal intake of food and water. Clinically symptoms remain same throughout the exposure periods.

\section{Hematological studies}

The effects of mosquito coil smoke and aerosol inhalation on hematological indices for control and exposed groups of animals are presented. RBC and WBC are significantly $(p<0.05)$ increased in both groups expose to mosquito coil and aerosol. After treating of vitamin $\mathrm{C}$ and vitamin $\mathrm{A}$ with inhaling aerosol, $\mathrm{RBC}$ and $\mathrm{WBC}$ were found to be decreased when compared with control groups (Fig. 1 and 2). 
Differential count of eosinophil's and basophils showed marginal changes in both mosquito coil smoke and aerosol exposed group, where the neutrophils increased significantly and the same time lymphocytes and monocytes were found to be decreased when compared with control (Fig. 3, 4 and 5).

\section{Histopathology of lung}

In unexposed control group, the transverse section of lung showed normal histological structures of trabecula with blood vessel, alveoli, ciliated epidermis, Respiratory bronchiole, Alveolar duct, alveolar sac, pulmonary artery and inter-alveolar septa (Plate 1). Where exposed to mosquito coil smoke and aerosol for 15, 30 and 45 days, the following histological abnormalities were recorded.

\section{Exposure of rats for 15 days with mosquito coil smoke}

Section of lung showing thickening and infiltration of mononuclear cells in the interstitial space, distortion of inter alveolar septa (arrow), congestion and hemorrhages in the alveoli, hypertrophied and hyperplastic bronchiolar cells $(*)$ were noticed after 15 days exposed to mosquito coli smoke (Plate 2).

\section{Exposure of rats for 15 days with aerosol}

Section of lung showing distortion of inter alveolar septa (arrow), degenerated the alveolar sac and hypertrophied and hyperplastic bronchiolar cells $(*)$ were revealed after 15 days exposed to mosquito aerosol (Plate 3).

\section{5 days post-treatment with vitamin $\mathrm{C}$ and} A

Section of lung from group IV (treatment to vitamin $\mathrm{C} \& A$ ) after 15 days showing bronchioles, trabeculi with blood vessels, alveoli with apparently thin inter alveolar septa, few cellular infiltration and congested blood vessels appeared near to control group (Plate 4).

\section{Exposure of rats for $\mathbf{3 0}$ days with mosquito coil smoke}

Section of lung showing inflammatory response, septa thickening and hyper cellularity and consolidation in alveolar area (arrow), thickening of bronchiolar epithelial wall, hypertrophied and hyperplasia of bronchiolar cells $(*)$ were noticed after 30 days of mosquito coil smoke exposure (Plate $6)$.

\section{Exposure of rats for 30 days with aerosol}

Section of lung showing more marked bronchiolar lesions (*), pulmonary emphysema characterized by distention and dilatation of alveoli was also evident at some places after 30 days post exposure to mosquito aerosol (Plate 7).

\section{0 days post-treatment with vitamin $\mathrm{C}$ and} A

Section of lung from group IV (treatment to vitamin $\mathrm{C} \& \mathrm{E}$ ) after 30 days showing respiratory bronchiole with blood vessels, alveoli with thin inter alveolar septa, alveolar sac appeared like control group (Plate 8).

\section{Exposure of rats for $\mathbf{4 5}$ days with mosquito coil smoke}

Section of lung showing distortion of respiratory bronchiole, degenerated the intra alveolar septa, many collapsed alveoli and cellular infiltration (arrow) was revealed after 45 days of mosquito coil smoke exposure (Plate 10). 


\section{Exposure of rats for $\mathbf{4 5}$ days with aerosol}

Section of lung showing extensive hypertrophy and hyperplasia of bronchiolar epithelial cells $(*)$ after 45 days of mosquito aerosol exposure (Plate 11).

\section{5 days post-treatment with vitamin $C$ and} A

Section of lung from group IV (treatment to vitamin $\mathrm{C} \& \mathrm{~A}$ ) after 45 days showing respiratory bronchiole with blood vessels, alveoli with thin inter alveolar septa, alveolar sac appeared like control group (Plate 12).

Environmental pollution and its impact on human being have well recognized during few decades. The role of air pollutants causing health hazards substances are distributed widely in ecosystems due to diverse human activities. The present study which was designed to mimic the local and everyday use of insecticides in residential areas using rats as model demonstrates the potential health implications of mosquito coil smoke exposure. Mosquito coils are widely used as mosquito repellent. Most of mosquito coils consists of an active ingredient known as pyrethroids, consists of about $0.3-0.4 \%$ of the coil mass. The combustion of mosquito coils generates large amounts of sub-micrometer particles and gaseous pollutants. These particles and cause the potential toxicological effects of the smoke on mammals (Thirumurugan et al., 2015). The present study shows that during autopsy lung parenchyma of the exposed animals were reddish to brownish in colour, microscopically parenchymatous blood vessels had mild congestion, thickening and infiltration of mononuclear cells in the interstitial space, distortion of inter alveolar septa, congestion and hemorrhages in the alveoli, hypertrophied and hyperplastic bronchiolar cells, pulmonary emphysema characterized by distention and dilatation of alveoli were noticed during exposure of mosquito coils and aerosol. Previous studies by Okine et al., (2004) using albino rats exposed to mosquito coil smoke showed that the smoke caused morphological changes in lung and the lung tissue showed thickening of the bronchiolar epithelial wall, alveolar septal thickening and hypercellularity, Clara cell hyperplasia, consolidation in alveolar areas, bronchopneumonia and emphysema, interstitial and pulmonary oedema, after 3 and 6 weeks of exposure which are indicative of toxicity of the mosquito repellent to the lung. Oedema could have resulted from the inflammatory processes taking place as a result of irritation of various organs by toxic chemicals from coil smoke. Other pathological manifestation that has been associated with pyrethroid mosquito coil but not observed in this study includes pneumonia, anthracosis, thrombosis and vasculitis, as observed by Taiwo et al., (2008).

Ayorinde et al., (2013) also reported the histological appearance of the lung tissues exposed to 1 repellent for 1, 2 and 4 weeks showed inflammation response consolidation in alveolar areas and septa thickening and thickening of bronchiolar epithelial wall in both male and female exposed animals. Kamble (2012) noticed that inhalation of mosquito repellent by rat caused selective damage to lung. Cheng et al., (1992), exposed rats to the mosquito coil smoke for 60 days resulted in focal delication to tracheal epithelium, metaplasia of epithelial cells and morphological alterations of alveolar macrophages.

Epidemiological studies have also shown that long term exposure to mosquito coil smoke can induce asthma and persistent wheeze in children and also showed abnormal growth of skin cells, per weight loss and lung damage 
(Azizi and Henry, 1991; Fagbule and Ekanem, 1994; Koo and Ho, 1994).

Recently, Idowu et al., (2013) evaluated histopathological abnormalities associated with mosquito coil smoke exposure in rats where lung showed mixed inflammatory cells, giant cell reaction, stromal fibrosis, inflammation and congestion of the interstitium, and hyperplasia of peribronchial lymphoid aggregates and congestion with pulmonary oedema after 16 weeks of exposure.

Exposure to mosquito coil smoke and aerosol for long time can have toxic effects on the hematological parameters and histopathology of lung as well as liver and kidney tissue also. Most vital organs like liver and kidney are seriously affected by mosquito coil smoke have been demonstrated by many researchers. Kidney tissues of exposed rats have revealed severe multifocal congestion, cystic dilation in the medulla, interstitial mononuclear cellular infiltration and wide spread fibrosis (Garba et al., 2007a, Taiwo et al., 2008), while damage to spleen revealed severe sinusoids hyperplasia and regression of red and white pulps (Garba et al., 2007).

Histopathological evaluation of mosquito coil effect had shown the impact on the kidney, 16 weeks post exposure, which demonstrates full congestion around the glomerular tuft, the study agrees with Taiwo et al., (2008) which demonstrated glomerula and tubular degeneration, necrosis, thrombosis and vasculitis to mosquito coil and varying insecticidal spray fumes in experimental rats. The study is also in line with earlier published work of Garba et al., (2007a) which demonstrated serve multifocal congestion, cystic dilation in the medulla of kidney tissue exposed to pyrethroid based mosquito coil.

Idowu et al., (2013) reported that the histological appearance of liver tissues exposed to mosquito coil smoke for two weeks showed extensive intracytoplasmic accumulations and moderate hydropic change. He also noticed that the liver tissues of rats exposed for four weeks showed generalized intracellular accumulations, and the cytoplasm appeared frosted and granular; there was also a mild hydropic change. At eight weeks of exposure, the liver tissues showed preserved architecture hepatocytes displayed as radiating plates and uniformly eosiniphilic cytoplasm, while liver tissues of rats exposed for 12 and 16 weeks, showed generalized intracellular accumulations and severe sinusoidal congestion. Okine et al., (2004) also observed fatty infiltration and proliferation of liver cells of mosquito coil smoke inhaled rats. Exposure to mosquito coil smoke decreases the protein biosynthetic activity of the liver. This could affect capacity of serum protein-mediated transport of various substances (Okine et al., 2004). Mosquito coil smoke exposure challenge the immune system in experimental rat leading to decreased in neutrophil and lymphocyte count as well as mean body weight (Garba et al., 2007). In the present study, it was found that total number of $\mathrm{RBC}$ and $\mathrm{WBC}$ are significantly increased in both groups expose to mosquito coil and aerosol. After treating of vitamin $\mathrm{C}$ and vitamin $\mathrm{A}$ with inhaling aerosol, RBC and WBC were found to be decreased when compared with control groups. Differential count of eosinophil's and basophils showed marginal changes in both mosquito coil smoke and aerosol exposed group, where the neutrophils increased significantly and the same time lymphocytes and monocytes were found to be decreased when compared with control. These results are compatible with those of Garba et al., (2007), who reported that inhalation of mosquito coil smoke for 28 days in albino rats showed RBC and WBC counts were significantly $(\mathrm{p}<0.01,0.05)$ increased in all the groups. Differential leucocytes counts 
analysis showed a decrease in neutrophils and lymphocytes percentages and also basophils counts were significantly increased in albino rats that were expose to mosquito coil smoke for 14 days respectively. Idowu et al., (2013) observed that significant increases in RBC, $\mathrm{WBC}$ and $\mathrm{PCV}$ in albino rats exposed to mosquito coil smoke for 16 weeks.

The significant increase in RBC and WBC in rats exposed to mosquito coil smoke and aerosol for 45 days may be due to pyrethroid which is a byproduct of mosquito coil smoke which is known to cause reduction in oxygen carrying capacity of $\mathrm{RBC}$ leading reduced metabolism. The reduction of oxygen stimulates erythropoietin which in turn stimulates the bone marrow to produce RBC. These findings are in agreement with earlier workers (Parker et al., 1984; Schoeinig, 1995) which similarly observed increase in RBC in rats exposed to pyrethroid based mosquito coil smoke.

Fig.1 Effects of mosquito coil smoke and aerosol along with vitamin on RBC of albino rats. (Mean \pm S.E.; $\mathrm{p}<0.05, * * \mathrm{p}<0.01, * * * \mathrm{p}<0.001$, Students' $t$-test $)$
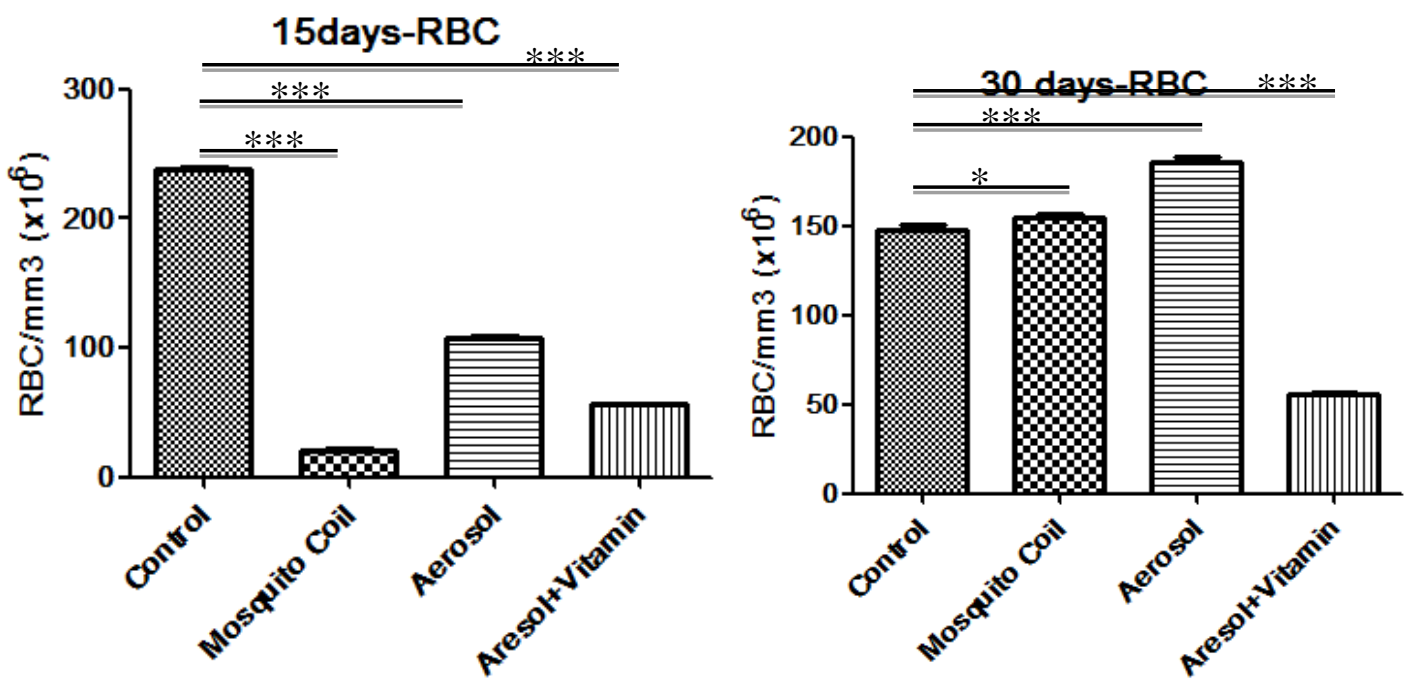

45 days-RBC

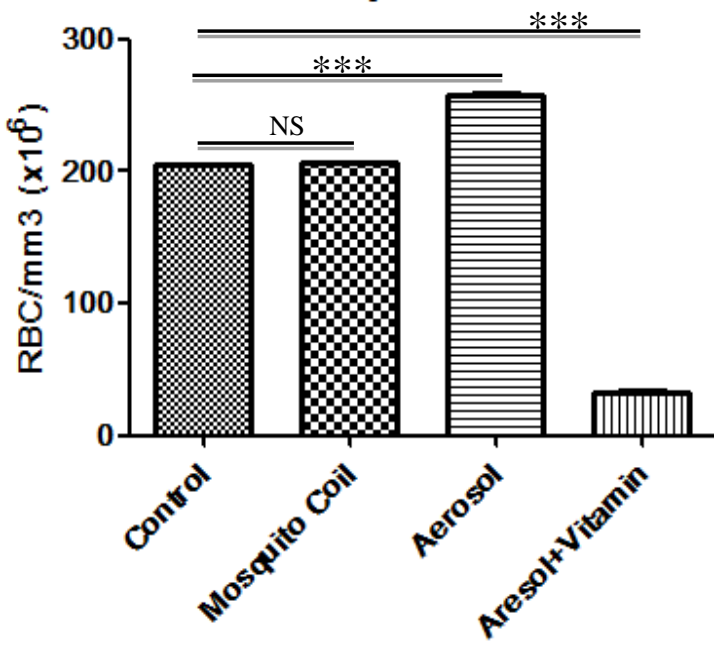


Fig.2 Effects of mosquito coil smoke and aerosol along with vitamin on WBC of albino rats.

(Mean \pm S.E.; $\mathrm{p}<0.05, * * \mathrm{p}<0.01, * * * \mathrm{p}<0.001$, Students' $t$-test $)$

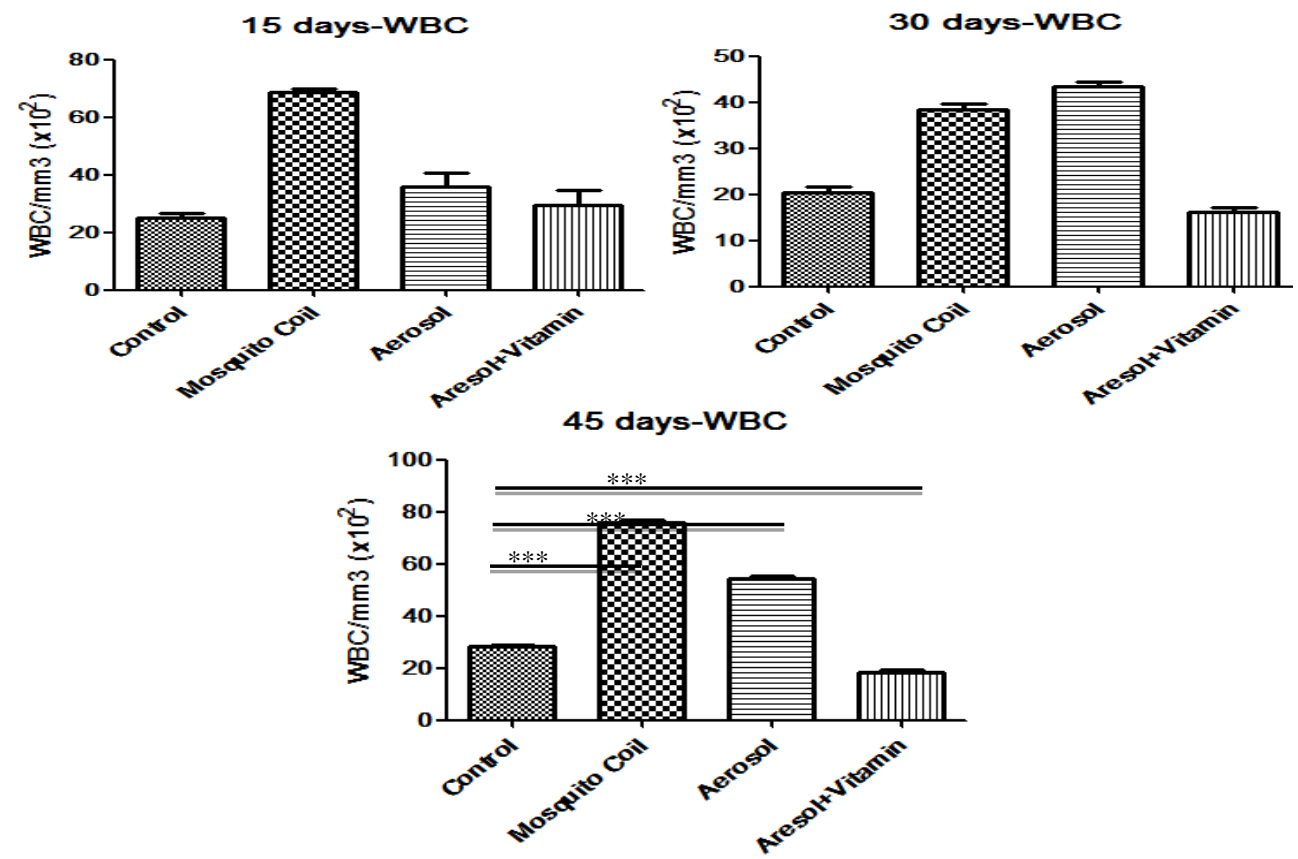

Fig.3 Differential counts of WBC for exposing animals for 15 days (Mean \pm S.E.; $\mathrm{p}<0.05$, $* * \mathrm{p}<0.01, * * * \mathrm{p}<0.001$, students' $t$-test)
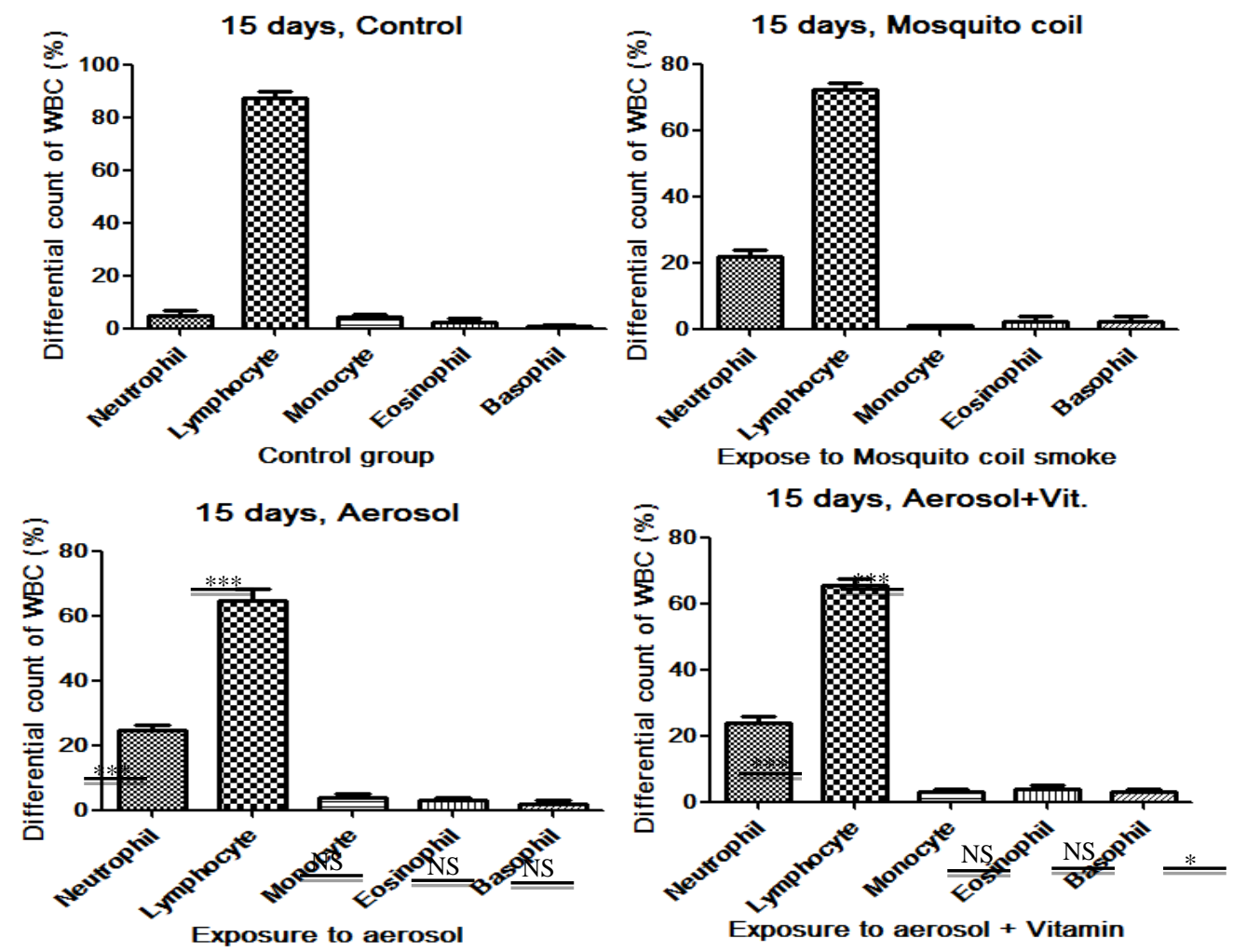
Fig.4 Differential counts of WBC for exposing animals for 30 days. (Mean \pm S.E.; $<<0.05$, $* * \mathrm{p}<0.01, * * * \mathrm{p}<0.001$, students' $t$-test)
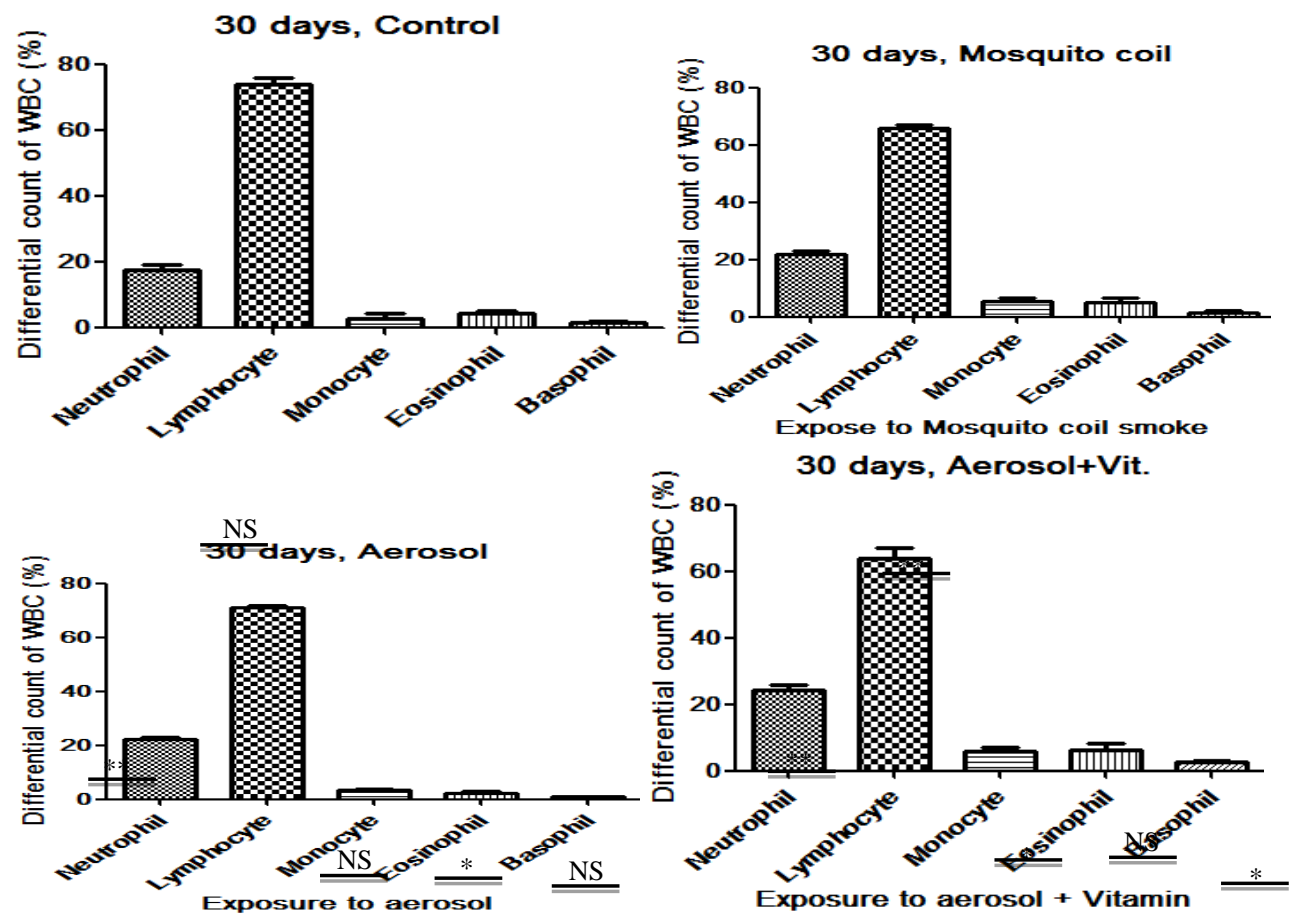

Fig.5 Differential counts of WBC for exposing animals for 45 days.(Mean \pm S.E.; $p<0.05$, $* * \mathrm{p}<0.01, * * * \mathrm{p}<0.001$, students' $t$-test $)$
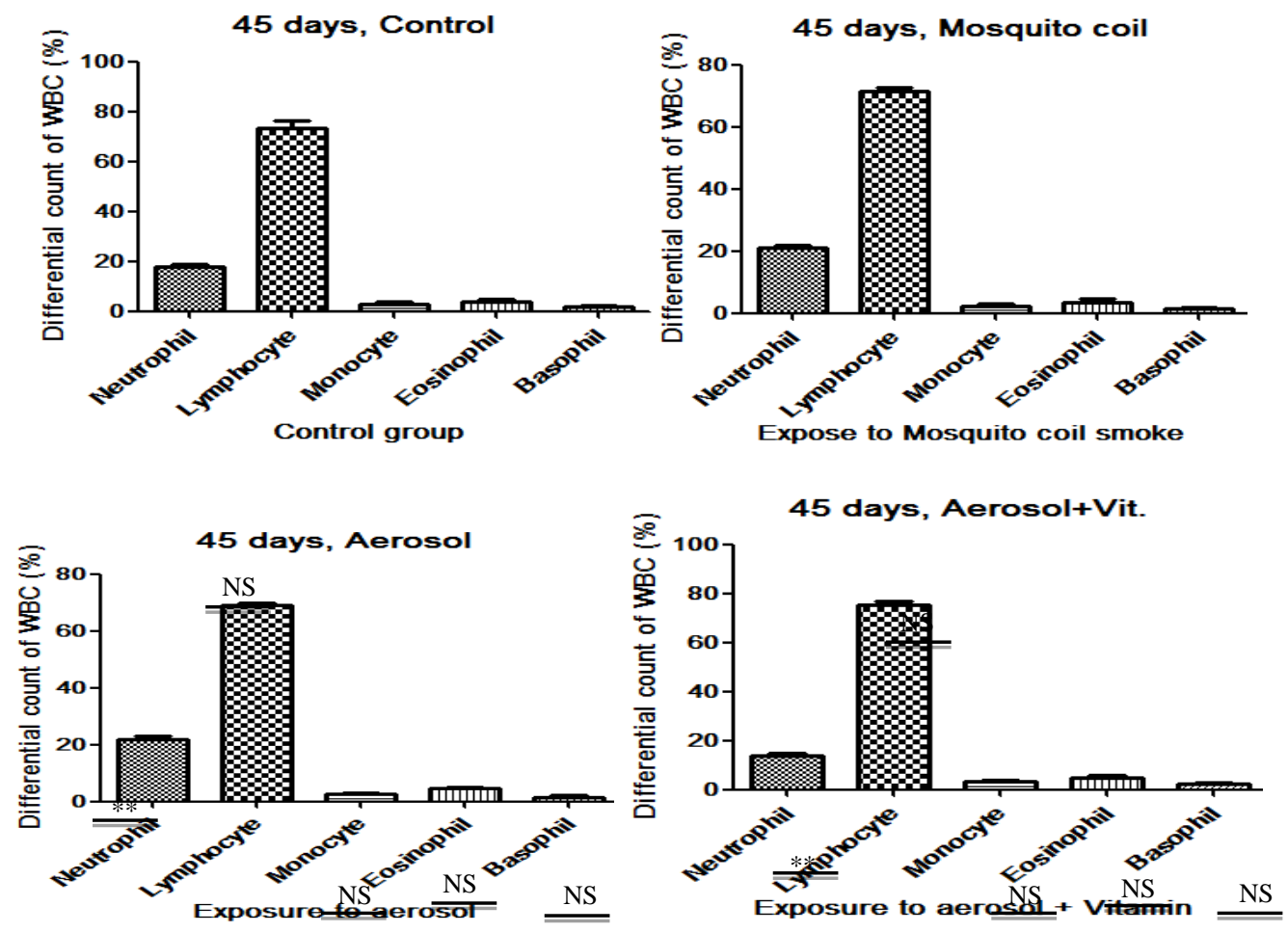


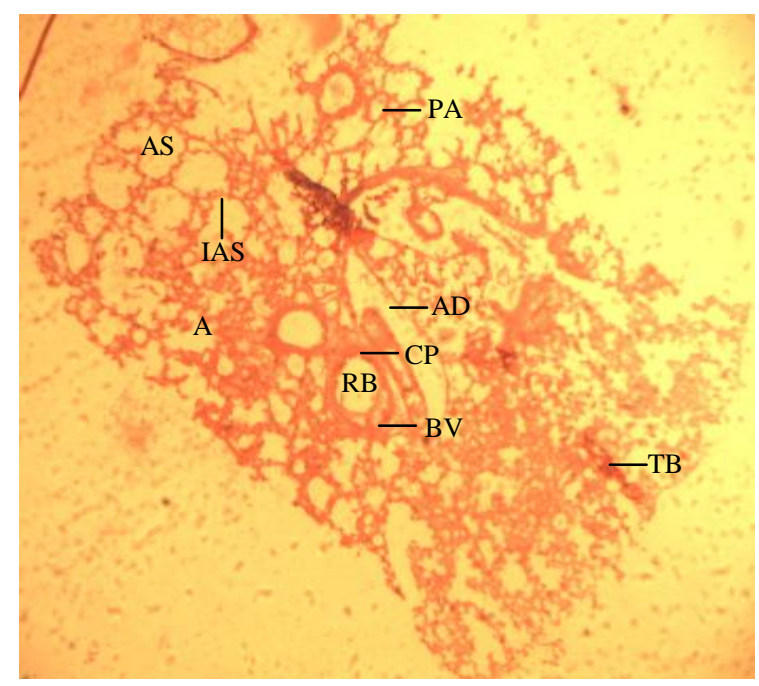

Plate.1 Section of lung from group I (control) after 15 days showing normal histological structure. Abbreviations: $\mathrm{A}=$ Alveoli, $\mathrm{CP}=$ Ciliated epidermis, $\quad \mathrm{RB}=$ Respiratory bronchiole, $\mathrm{AD}=$ Alveolar duct, $\mathrm{AS}=$ Alveolar sac, BV=Blood vessels, PA=Pulmonary artery, $\mathrm{TB}=$ Trabecula with blood vessel, IAS=Interalveolar septa. (Mag. $x$ 400)

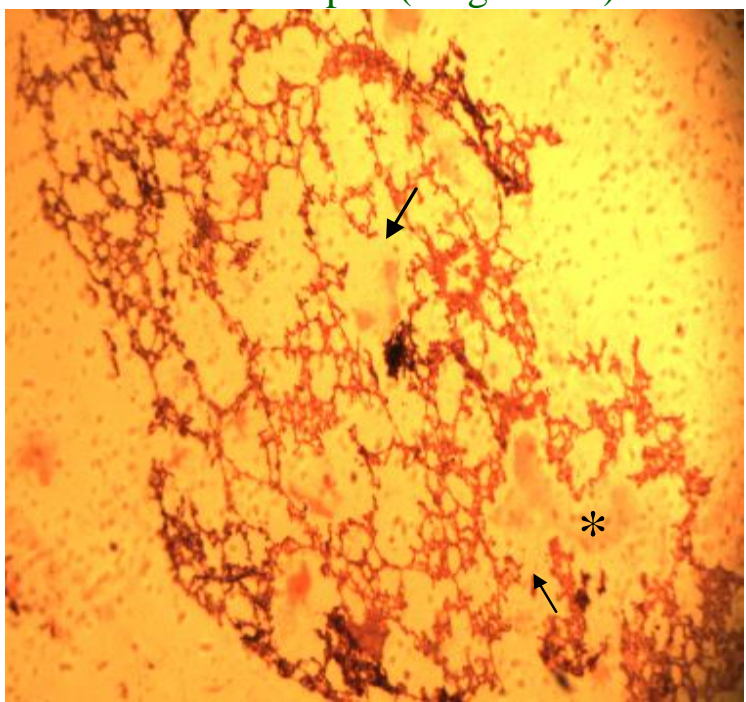

Plate.3 Section of lung showing distortion of inter alveolar septa (arrow), degenerated the alveolar sac and hypertrophied and hyperplastic bronchiolar cells (*) were revealed after 15 days exposed to mosquito aerosol. (x 400)

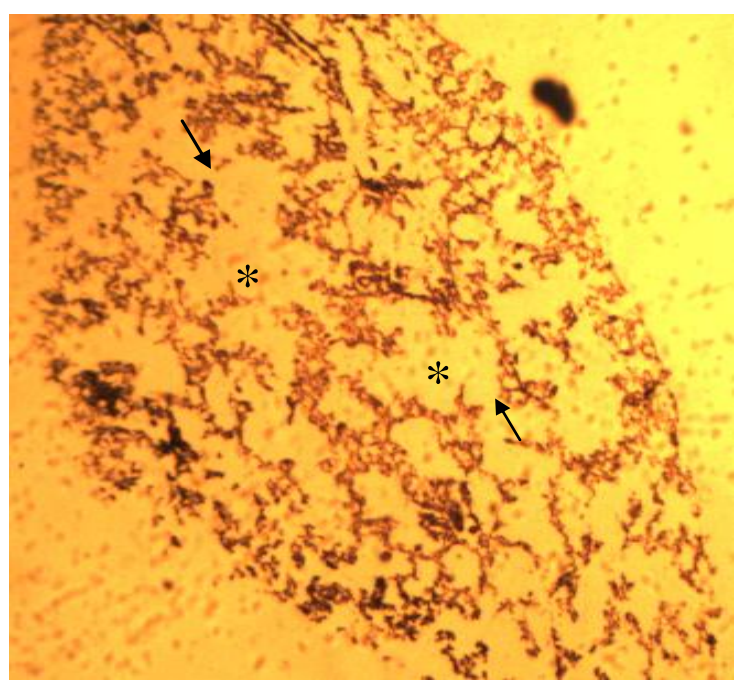

Plate.2 Section of lung showing thickening and infiltration of mononuclear cells in the interstitial space, distortion of inter alveolar septa (arrow), congestion and hemorrhages in the alveoli, hypertrophied and hyperplastic bronchiolar cells $(*)$ were noticed after 15 days exposed to mosquito coli smoke. (x 400)

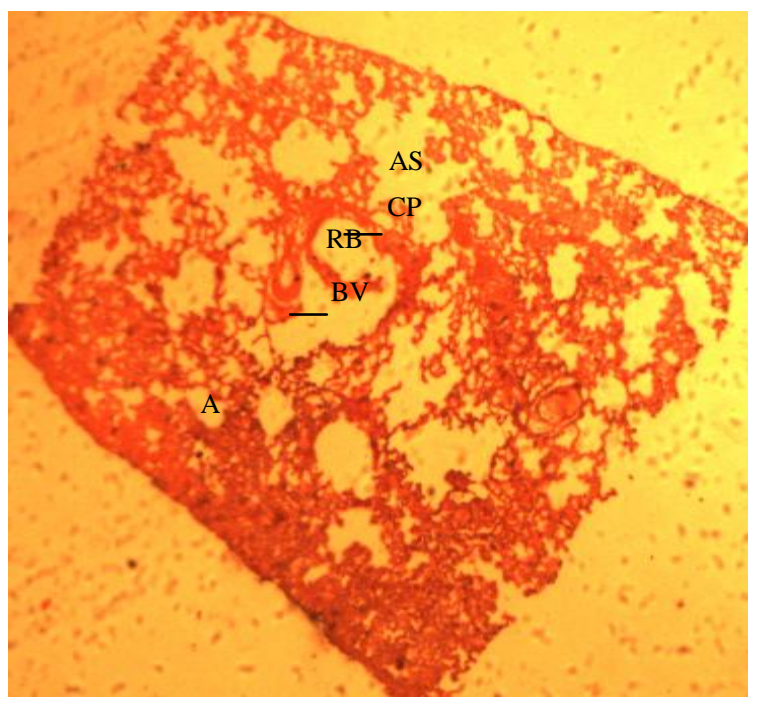

Plate.4 Section of lung from group IV (treatment to vitamin $\mathrm{C} \& \mathrm{~A}$ ) after 15 days showing bronchioles, Trabeculi with blood vessels, Alveoli with apparently thin inter alveolar septa, few cellular infiltration and congested blood vessels appeared near to control group. (x 400) 


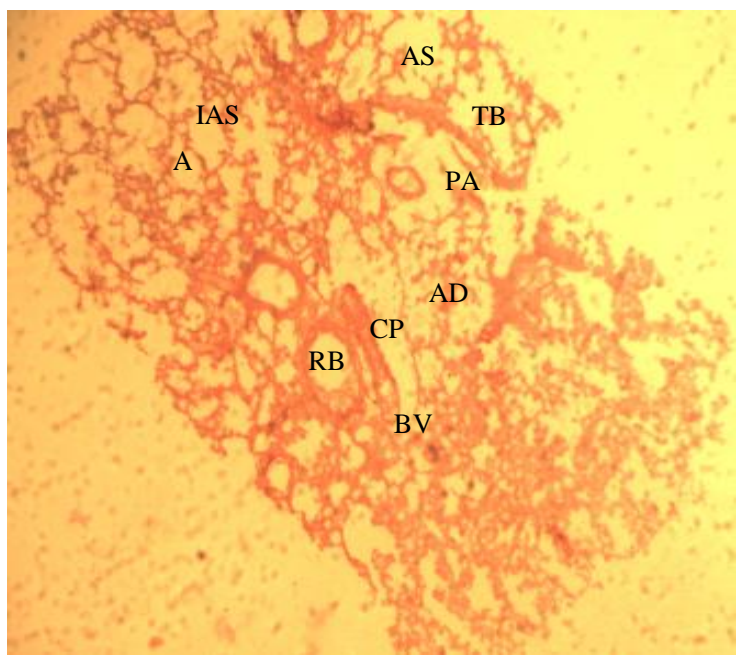

Plate.5 Section of lung from group I (control) after 30 days showing normal histological structure. Abbreviations: $\mathrm{A}=\mathrm{Alveoli}, \mathrm{CP}=$ Ciliated epidermis, $\quad \mathrm{RB}=$ Respiratory bronchiole, $\mathrm{AD}=$ Alveolar duct, $\mathrm{AS}=$ Alveolar sac, $\mathrm{BV}=$ Blood vessels, $\mathrm{PA}=$ Pulmonary artery, $\mathrm{TB}=$ Trabecula with blood vessel, IAS=Interalveolar septa. (Mag. X 400)

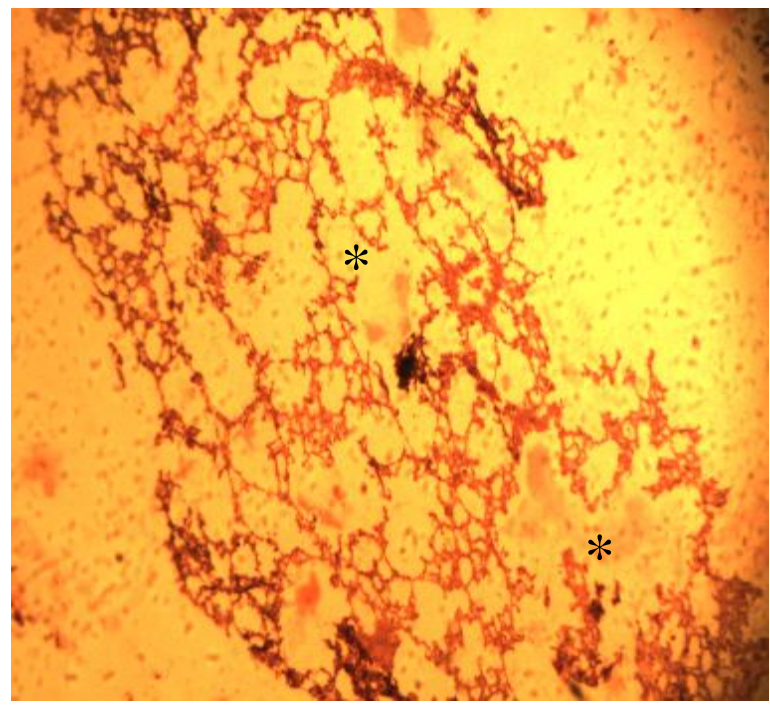

Plate.7 Section of lung showing more marked bronchiolar lesions $(*)$, pulmonary emphysema characterized by distention and dilatation of alveoli was also evident at some places after 30 days post exposure to mosquito aerosol.(x 400)

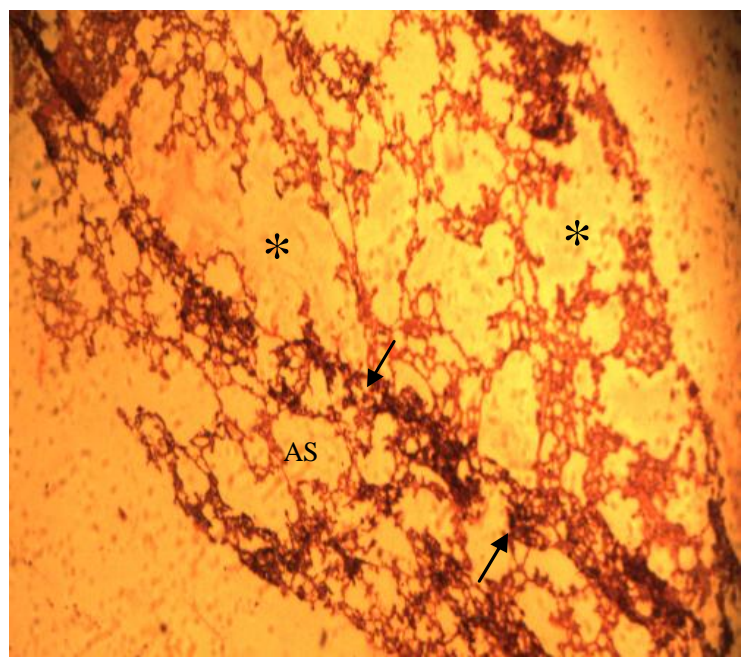

Plate.6 Section of lung showing inflammatory response, septa thickening and hyper cellularity and consolidation in alveolar area (arrow), thickening of bronchiolar epithelial wall, hypertrophied and hyperplasia of bronchiolar cells (*) were noticed after 30 days of mosquito coil smoke exposure. (x 400)

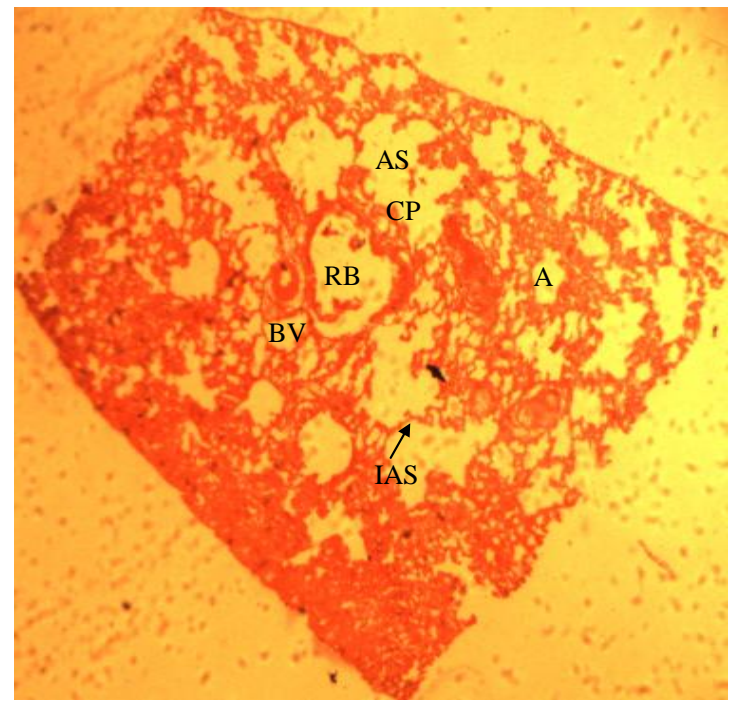

Plate.8 Section of lung from group IV (treatment to vitamin C \& A) after 30 days showing respiratory bronchiole with blood vessels, alveoli with thin inter alveolar septa, alveolar sac appeared like control group.(x400) 


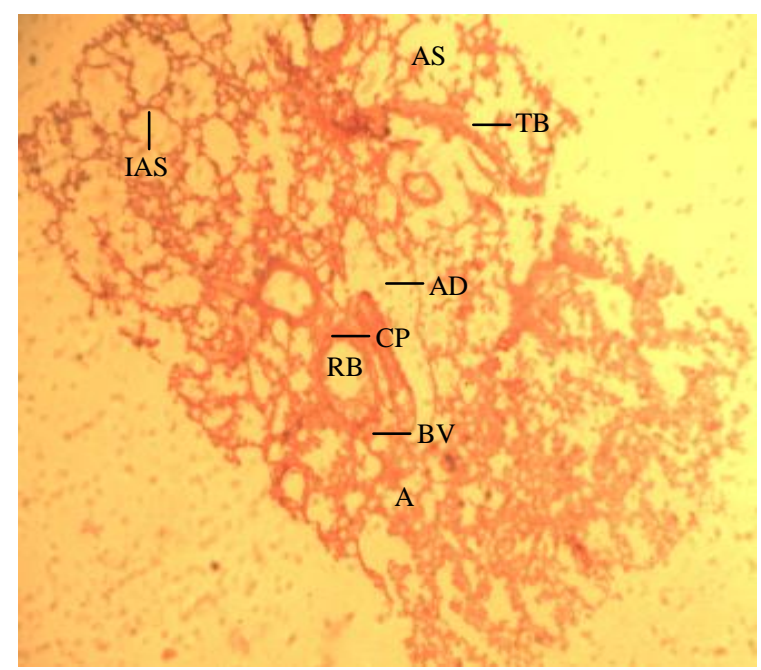

Plate.9 Section of lung from group I (control) after 45 days showing normal histological structure. Abbreviations: $\mathrm{A}=$ Alveoli, $\mathrm{CP}=$ Ciliated epidermis, $\quad \mathrm{RB}=$ Respiratory bronchiole, $\mathrm{AD}=$ Alveolar duct, $\mathrm{AS}=\mathrm{Alveolar}$ sac, $\mathrm{BV}=$ Blood vessels, $\mathrm{PA}=$ Pulmonary artery, $\mathrm{TB}=$ Trabecula with blood vessel, IAS=Interalveolar septa. (Mag. $x$ 400)

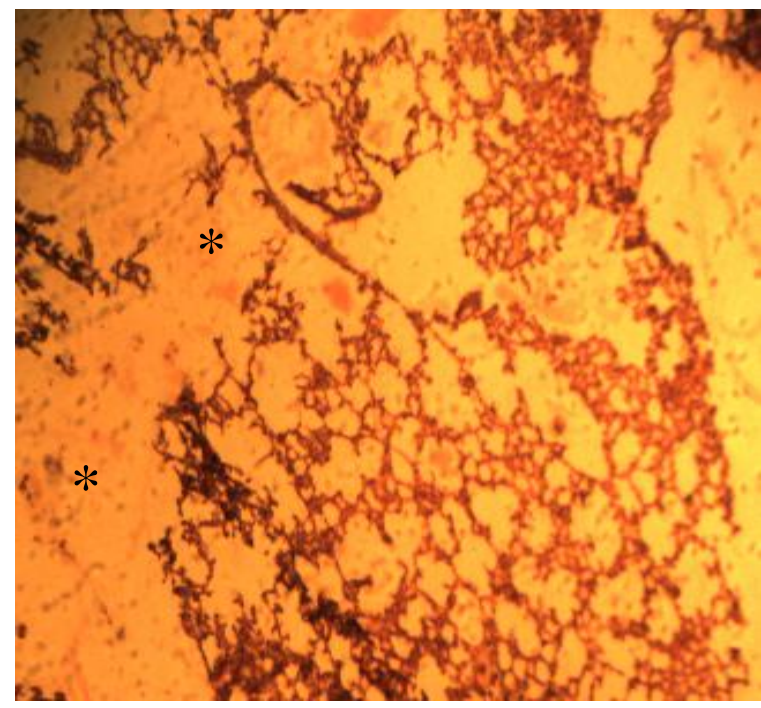

Plate.11 Section of lung showing extensive hypertrophy and hyperplasia of bronchiolar epithelial cells (*) after 45 days of mosquito aerosol exposure.(x 400)

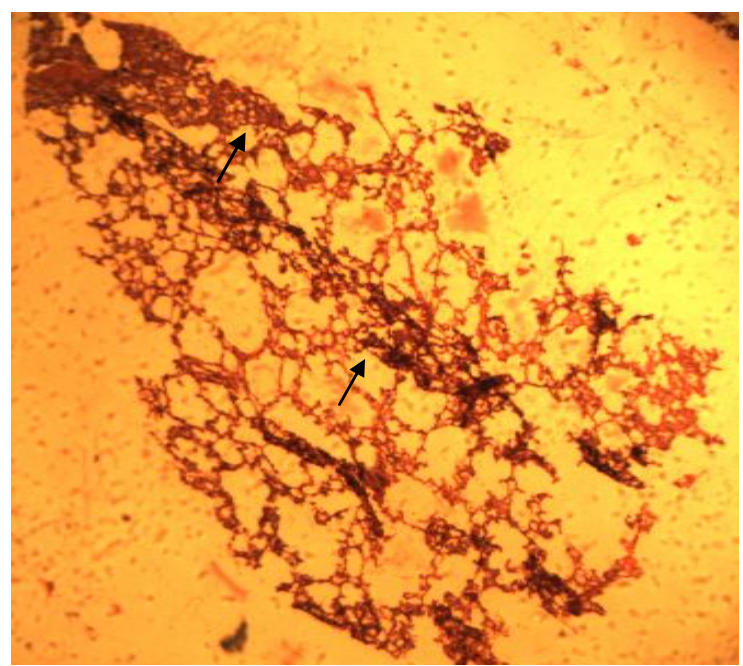

Plate.10 Section of lung showing distortion of respiratory bronchiole, degenerated the intra alveolar septa, many collapsed alveoli and cellular infiltration (arrow) was revealed after 45 days of mosquito coil smoke exposure. (x 400)

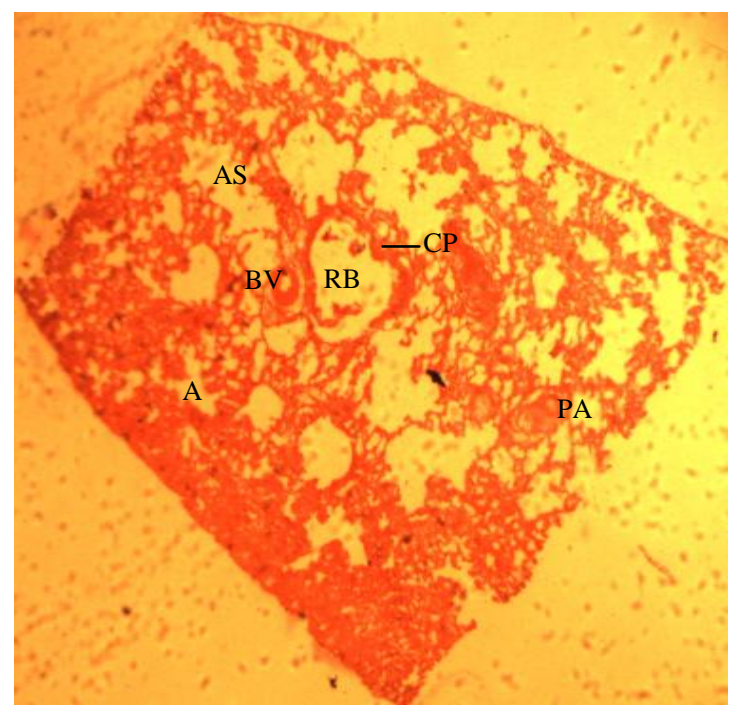

Plate.12 Section of lung from group IV (treatment to vitamin C \& A) after 45 days showing respiratory bronchiole with blood vessels, alveoli with thin inter alveolar septa, alveolar sac appeared like control group.(x400) 
Sunyer et al., (1996) recorded a higher White Blood Cell count in smokers compared with non-smokers and Al-Awadhi et al., (2008) reported the effects of smoke on white blood cell count. Aboderin and Oyetayo (2006) reported that $\mathrm{WBC}$ are important in defending the body against infection. Also that presence of Basophils counts is an indication of increase in sensitization to an antigen or (allergen). According to Oladunmoye (2006), T-lymphocytes and other key cells of the immune system are known to activate production of antibody to destroy evading pathogen.

The increase in the lymphocyte count, WBC and other white blood cells in the exposed animal in this study show sign of immunestimulatory effect of the mosquito repellent on the animals.

The basophilic leukocytosis observed in this study could be ascribed to an acute inflammatory response to pulmonary irritation, because signs of respiratory irritation have been reported in human (Lessenger, 1992) and in laboratory animals (Flucke and Thyssen, 1980; Hext, 1987) that were exposed to pyrethrins so also is the immunological and lymphoreteticular effects that have also been reported in a human subject in which elevated levels of $\operatorname{IgG}, \operatorname{IgM}$, and $\operatorname{IgE}$ were observed following repeated indoor use of a pyrethrum based insecticide (Carlson and Villaveces, 1977). Subsequent skin tests resulted in skin reactions and allergic pulmonary response to pyrethroids. This also agrees with a similar result from a pyrethroid poisoning in a human subject (He et al., 1989). Eosinophilic Chemotactic Factor (ECF) is released from basophils as well as IL-5, which causes eosinophilic leukocytosis by increasing the differentiation of eosinophilic precursor cells. Basophils express receptors for IgE complexed antigens which are phagocytosed in a non-specific manner by neutrophils and macrophages.
Eosinophils modulate the sometimes hazardous effect of basophils and the eosinophilic leukocytosis observed in this study could be attributed to this fact.

Hypersensitivity pneumonitis is associated with shortness of breath over a period of time could cause a significant decrease of $\mathrm{O}_{2}$ delivery to the tissues. This hypoxic situation could lead to the stimulation of erythropoietin synthesizing cells to express erythropoietin and hence stimulate red blood cell production. This could be responsible for the increased number of red blood cells observed in the course of this study, with a significant increase observed in aerosol and mosquito coil smoke exposed rats for the longest period.

In conclusion, exposure to mosquito coil smoke and aerosol sprays for a long period of time can have toxic effects on the hematological parameters and histopathology of the lung. The tissue of the lungs can be affected by a number of diseases, including pneumonia and lung cancer. Chronic diseases such as chronic obstructive pulmonary disease and emphysema can be related to smoking or exposure to harmful substances. It is possible that chronic inhalation of mosquito coil smoke in humans may also be harmful and this will be investigated and to study the mechanism of its toxicity and reversibility/irreversibility the pathological effects is recommended in further studies.

\section{Acknowledgements}

This forms part of MS research by Alpona Sarkar Hasi. Co-operations offered by the Laboratory Attendants are thankfully acknowledged. The Chairman, Department of Zoology, University of Rajshahi, Bangladesh, deserves special thanks for providing laboratory facilities. 


\section{References}

Aboderin, F.I., and Oyetayo, V.O. 2006. Haemotological studies of rats fed different doses of probiotic, Lactobacillus plantarum, isolated from fermenting corn slurry. Pak J Nutr., 5: 102-105.

Al-Awadhi, A.M., Alfadhli, S.M., Mustafa, N.Y., Sharma, P.N. 2008. Effects of cigarette smoking on hematological parameters and von Willebrand factor functional activity levels in asymptomatic male and female Arab smokers. Med Princ Pract., 17: 149-153.

Ayorinde, A.F., Oboh, B.O., Otubanjo, O.A., Alimba, A.C., Odeigah, P.C. 2013. Some Toxicological Effects of a Commonly Used Mosquito Repellent in Lagos State, Nigeria. Research Journal of Environmental Toxicology.

Azizi, B.H., and Henry, R.L. 1991. The effects of indoor environmental factors on respiratory illness in primary school children in Kualalumpur. International journal of epidimoilogy, 20: 144-149.

Bashirullah, A.K.M., and Elahi, K.M. 1972a. On two new species of Genarchopsis ozaki 1925 from freshwater fishes of Dacca, Bangladesh. Riv. Parasitol, 33: 277-280.

Bashirullah, A.K.M., and Elahi, K.M. 1972b. Three trematodes (Allocreadiidae) from the freshwater fishes of Dacca, Bangladesh. Norwegian Journal of Zoology, 20: 205-208.

Carlson, J.E., and Villaveces, J.W. 1977. Hypersensitivity pneumonitis due to pyrethrum: Report of a case. J Am Med Assoc., 237: 1718-1719.

Cheng, V., Lee, H.R., Chen, C.S. 1992. Morphological changes in the respiratory system of mice after inhalation of mosquito-coil smoke. Toxicol Len., 26:163-177.

Chang, J., and Lin, J. 1998. Aliphatic aldehydes and allethrin in mosquito coil smoke. Chemosphere, 36(3): 617-624.

Fagbule, D., and Ekanein, E.E. 1994. Some environmental risk factors for childhood asthma: A case-control study. Ann Trop Paediatr., 14: 15-19.

Flucke, W., and Thyssen. 1980. Acute toxicity studies. Institut fur Toxikologie. OTS0543768.

Garba, S.H., Shehu, M.M., Adelaiye, A.B. 2007a. Toxicological effects of inhaled mosquito coil smoke on the rat spleen. A haematological and histological study. $J$ Med Sci., 7(1): 94-99.

Garba, S.H., Adelaiye, A.B., Mshelia, L.Y. 2007. Histopathological and biochemical changes in the rats kidney following exposure to a pyrethroid based mosquito coil. Journal of Applied Sciences Research, 3(12):1788-1793.

Hoffman, G.L. 1967. Parasites of the Northern American freshwater fishes, University of California Press, Berkeley and Los Angeles.

He, F., Wang, S., Liu, L. 1989. Clinical manifestations and diagnosis of acute pyrethroid poisoning. Arch Toxicol., 63: 54-58.

Hext, P.M., 1987. 4-Hour acute inhalation toxicity study in the rat. Imperical Chemical Industris PLC. OTS0545653. Pp321.

Idowu, E.T., Aimufua, O.J., Ejovwoke, Y.O., Akinsanya, B., Otubanjo, O.A. 2013. Toxicological effects of prolonged and intense use of mosquito coil emission in rats and its implications on malaria control. Rev Biol Trop., 61(3): 14631473.

Kamble, V.S., 2012. Study of chronic treatment of mosquito repellant liquid inhalation on bio-chemical constituents of rat. International Journal of Applied Biology and Pharmaceutical Biology. 3: 189-192.

Koo, L.C.L., and Ho, J.H.C. 1994. Mosquito 
coil smoke and respiratory health among Hong Kong Chinese epidemiological studies. Indoor Environ., 3:304-310.

Krieger, R.L., Dinoff, T.M., Zhang, X. 2003. Octachlomdipropyl ether (5-2) mosquito coils are inadequately studied for residential use in Asia and illegal in the United States. Environmental Health Perspectives, 111: 12.

Lesserger, J.E., 1992. Five office workers in advertently exposed to cypermethrin. $J$ Toxicol Environ Health, 35: 261-267.

Mulla, M.S., Thavara, U., Tawatsin, A., Kong-Ngamsuk, W., Champoosri. 2001. Mosquito burden and impact on the poor; measures and costa for personal protection in some, communities in Thailand. J Am Mosquito Control Assay, 17: 153-159.

Okine, L.K.N., Nyarko, A.K., Armah, G.E., Awumbila, B., Owusa, K., Setsoafla, S., Ofosuhene, M. 2004. Adverse Effects of Mosquito Coil Smoke on Lung, Liver and Certain Drugs Metabolising Enzymes in Male Albino Wistar Rats. Ghana Medical Journal, 38(2): 8-14.

Oladunmoye, $\quad$ M.K., 2006. Immunomodulatory effects of ehanoic extract of Tridar procumber on swiss albino rats oral-gastrically dosed with Pseudomonas aeniginosa (NCIB 950). Int J Trop Med., 1: 152-155.

Parker, C.M., Patterson, D.R., Van, G.A. 1984. Chronic toxicity and carcinogenicity evaluation of fenvalerate in rats. J Toxicol Environ Health, 13: 83-97.

Schoenig, G.P. 1995. Mammalian Toxicology of Pyrethrum Extract. In E. Casida and G.B. Quistad (eds.). Pyrethrum Flowers: Production, Chemistry, Toxicology and Uses. Oxford, New York, USA. 249257.

Sultana, A., Raheman, M., Hossain, M. 2015. Household pesticides and their practices in Dhaka City. Bangladesh J Zool., 43(1): 137-139.

Sunyer, J., Munoz, A., Peng, Y., Margolick, J., Chennai, J.S. 1996. Longitudinal relation between smoking and white blood cells. Am J Epid., 144: 734-741.

Taiwo, V.O., Nwagbara, N.D., Suleiman, R., Angbashim, J.E., Zarma, M.J. 2008. Clinical signs and organ pathology in rats exposed to graded doses of pyrethroids containing mosquito coil smoke and aerosolized insecticidal sprays. African Journal of Biomedical Research, 11: 97-104.

Thirumuruman, P., Senthamil, S.P., Yamini, P.V., Dhanasekar, L. 2015. Impact of Hemidesmus indicus on mosquito coil exposed rat. Journal of Medicinal Plant Studies, 3(6):19-23.

World Health Organization (WHO). 2005. Indoor air pollution and child health in Pakistan: report of seminar held at the Aga Khan University, Karachi, Pakistan.

\section{How to cite this article:}

Moni Krishno Mohanta, Alpona Sarker Hasi, Md. Fazlul Haque and Ananda Kumar Saha. 2019. Supplementation of Vitamin A and C can Effectively Recover the Histological and Haematological Alteration caused by Mosquito Coil Smoke and Aerosol in Mice Model. Int.J.Curr.Microbiol.App.Sci. 8(05): 2223-2237. doi: https://doi.org/10.20546/ijcmas.2019.805.262 